\title{
SIMILITUDES Y DIFERENCIAS ENTRE EL DIARIO DEL AÑO DE LA PESTE Y LA ENFERMEDAD POR COVID-19
}

\section{Similarities and differences between a Journal of the plague year and COVID-19}

\author{
Sara DE ARRIBA IGLESIAS¹; Agustín HIDALGO BALSERA². \\ ${ }^{1}$ Facultad de Medicina y Ciencias de la Salud. Universidad de Oviedo. ${ }^{2}$ Área de Farmacología, Departamento \\ de Medicina, Universidad de Oviedo. Instituto Universitario de Oncología del Principado de Asturias (IUOPA), \\ Fundación Cajastur. Instituto de Investigación Sanitaria de Asturias (ISPA) (España). \\ Correos electrónicos: hidalgo@uniovi.es, saradearribaiglesias@outlook.com
}

Recibido: 11 de agosto de 2021

Aceptado: 16 de agosto de 2021

\section{Resumen}

La literatura sobre enfermedad -particularmente, sobre epidemias- cuenta con numerosos recursos a la hora de permitirnos profundizar en el conocimiento de la noxa desde un punto de vista no sólo nosológico, sino también sociológico. El presente trabajo analiza éstos y otros aspectos relevantes que se pueden extraer de la lectura de "El Diario del año de la peste», en contraposición a la situación derivada de la pandemia por el Sars-Cov-2. Se han encontrado similitudes significativas entre ambos procesos, sobre todo en lo relativo a las medidas públicas adoptadas y la respuesta social, así como diferencias sustanciales que pueden tener su base en el desarrollo científico-tecnológico que ha culminado en la obtención de las vacunas frente a la Covid 19 en un tiempo récord. Si bien cada epidemia es única, su estudio comparado puede aportar una visión global que sirva de aprendizaje y guía para afrontar posibles crisis sanitarias futuras.

Palabras clave: epidemias literarias, peste bubónica, pandemia, Covid 19.

\section{Summary}

Literature about disease -particularly about epidemics- involves numerous resources that allow us to deepen our knowledge of the noxa not only from a nosological point of view, but also from a sociological one. This paper analyzes these and other relevant aspects that can be 


\section{SIMILITUDES Y DIFERENCIAS ENTRE EL DIARIO DEL AÑO DE LA PESTE \\ Y LA ENFERMEDAD POR COVID-19 \\ SARA DE ARRIBA IGLESIAS; AGUSTÍN HIDALGO BALSERA}

extracted from the reading of "A Journal of the Plague Year», as opposed to the situation derived from the Sars-Cov-2 pandemic. Significant similarities have been found between both processes, especially regarding to the public measures adopted and the social response, as well as substantial differences that may be based on the scientific-technological development that has culminated in obtaining vaccines against Covid 19 in the shortest time. Although each epidemic is unique, its comparative study can provide us with a global vision that coud helps us learn and guide us when facing possible future health crises.

Keywords: literary epidemics, bubonic plague, pandemic, Covid 19.

"Fantaseamos, ajenos al peligro real, sobre la revolución de las máquinas y la esclavitud del hombre por la inteligencia artificial, tenemos pesadillas con la singularidad tecnológica. $Y$, no obstante, es posible que muy pronto un virus asesine al setenta y cinco por ciento de la población mundial» ${ }^{1}$.

\section{Introducción}

Medicina y literatura son dos disciplinas que históricamente han establecido un mecanismo de feedback muy intenso, desde los tiempos de Hipócrates hasta nuestros días, siendo la palabra "el vínculo de unión entre la literatura y la medicina [...]. Pero además, la medicina y la literatura reconocen el mismo objeto: la persona humana, el hombre en todas sus manifestaciones culturales, porque pensamos, soñamos y sufrimos en códigos verbales. $\|^{2}$

La literatura -en todos sus géneros y subgéneros- sobre epidemias ya era profusa, y a tenor de la situación actual no deja de generarse más (Tabla 1). Los géneros literarios van desde el ensayo a la poesía pasando por la novela, la divulgación científica o el cómic. En buena medida, estos textos reúnen una serie de características generales, que hemos definido previamente ${ }^{3} y$ de los que, a efectos de este artículo, es importante que a) cuentan historias únicas: aludiendo a la individualidad, y a la forma diferenciada de experimentar el proceso de cada persona; b) proponen un papel educativo para la enfermedad: se ofrece casi como una oportunidad, ya que "nos expone a una nueva situación extraordinaria ante la que hemos de desarrollar estrategias de entendimiento, aceptación, convivencia y superación " '; c) Reconocen la limitación del lenguaje para expresar lo que se siente: a este respecto, se emplean diferentes recursos, entre los que destacan los neologismos y las metáforas tales como las bélicas (guerra, soldados, héroes,...) ${ }^{4}$ aunque, en opinión de Susan Sontag "el modo más auténtico de encarar la enfermedad - y el modo más sano de estar enfermo- es el que menos se presta y mejor resiste al pensamiento metafórico» ${ }^{5}$; d) el tema del lenguaje y el uso que se hace de él en los medios preocupa y es relevante hasta el punto de estar regulado por la OMS. Como nos recuerdan en El Jinete Pálido: "La Organización Mundial de la Salud publicó en 2015 unas directrices que estipulan que los nombres de las enfermedades no deben hacer referencia a lugares, personas, animales o alimentos concretos. No deben incluir palabras que susciten miedo, como "mortal» o "desconocido». En cambio, se deben usar términos descriptivos genéricos basados en los síntomas, como "enfermedad respiratoria", junto con términos descriptivos más específicos, como "juvenil» o "costera», y el nombre del agente causante de la enfermedad. Cuando surge la necesidad de diferenciar entre 


\section{SIMILITUDES Y DIFERENCIAS ENTRE EL DIARIO DEL AÑO DE LA PESTE \\ Y LA ENFERMEDAD POR COVID-19 \\ SARA DE ARRIBA IGLESIAS; AGUSTÍN HIDALGO BALSERA}

Tabla 1. relación de referencias publicadas sobre literatura epidémica y pandémica.

\begin{tabular}{|c|c|c|c|}
\hline TÍTULO & GÉNERO & AUTOR & AÑO \\
\hline Diario del año de la peste & Novela & Daniel Defoe & 1772 \\
\hline $\begin{array}{l}\text { Preámbulo a la primera jornada de } \\
\text { Decamerone }\end{array}$ & Cuento & $\begin{array}{l}\text { Giovanni } \\
\text { Bocaccio }\end{array}$ & $1348-1353$ \\
\hline La historia de San Michele & Novela & Axel Munthe & 1929 \\
\hline Pabellón de reposo & Novela & Camilo José Cela & 1943 \\
\hline La peste & Novela & Albert Camus & 1947 \\
\hline Al amigo que no me salvó la vida & Testimonial & Hervé Guibert & 1990 \\
\hline Píldoras azules & Testimonial & Frederik Peteers & 2001 \\
\hline Nemesis & Novela & Philip Roth & 2010 \\
\hline Historia de las epidemias & Divulgación & Matías Alinovi & 2009 \\
\hline Viral & Divulgación & Juan Fueyo & 2021 \\
\hline Ensayo sobre la ceguera & Novela & José Saramago & 1995 \\
\hline Apocalipsis & Novela & Stephen King & 1978 \\
\hline El último hombre & Novela & Mary Shelley & 1826 \\
\hline La máquina se para & Novela & $\begin{array}{l}\text { Edward Morgan } \\
\text { Forster }\end{array}$ & 2016 \\
\hline Historia de la guerra del Peloponeso & Historico & Tucídides & 430 a.C. \\
\hline Contra un enemigo mortal e invisible & Divulgación & Carlo M. Cipolla & 1993 \\
\hline Contagio & Divulgación & David Quammen & 2020 \\
\hline Las grandes epidemias modernas & Divulgación & Salvador Macip & 2020 \\
\hline Un día en la vida de un virus & Divulgación & Miguel Pita & 2020 \\
\hline Coronavirus & Divulgación & $\begin{array}{l}\text { Sonia de Miguel y } \\
\text { Juan Carlos Ruíz }\end{array}$ & 2020 \\
\hline Pandemia & Ensayo & Slavoj Zizek & 2020 \\
\hline ¿Ya es mañana? & Ensayo & Ivan Krastev & 2020 \\
\hline Pandemia & Ensayo & Iñaki Ribera & 2020 \\
\hline Pandemocracia & Ensayo & Daniel Innerarity & 2020 \\
\hline La tradición cosmopolita & Ensayo & $\begin{array}{l}\text { Martha } \\
\text { Nussbaum }\end{array}$ & 2020 \\
\hline En el contagio & Testimonial & Paolo Giordano & 2020 \\
\hline Diario de Wuhan & Testimonial & Fang-Fang & 2020 \\
\hline La vida en suspenso & Testimonial & Jordi Doce & 2020 \\
\hline Nación vacuna & Novela & $\begin{array}{l}\text { Fernanda García } \\
\text { Lao }\end{array}$ & 2020 \\
\hline Este virus que nos vuelve locos & Ensayo & Henri Levy & 2020 \\
\hline
\end{tabular}

Rev. Med. Cine. 2021; 17 (4), 315-335 Ediciones Universidad de Salamanca / @®@@ J. Med. Mov., 2021; 17 (4), $315-335$ 


\section{SIMILITUDES Y DIFERENCIAS ENTRE EL DIARIO DEL AÑO DE LA PESTE \\ Y LA ENFERMEDAD POR COVID-19}

SARA DE ARRIBA IGLESIAS; AGUSTÍN HIDALGO BALSERA

\begin{tabular}{|c|c|c|c|}
\hline TÍTULO & GÉNERO & AUTOR & AÑO \\
\hline La espera & Poesía & Manuel Vilas & 2020 \\
\hline Bosque & Poesía & Ada Salas & 2020 \\
\hline El hechizo & Poesía & Ana Merino & 2020 \\
\hline El enfermo & Poesía & $\begin{array}{l}\text { Felipe Benítez } \\
\text { Reyes }\end{array}$ & 2020 \\
\hline $\begin{array}{l}\text { Y la gente se quedó en casa (And the people stayed } \\
\text { home) }\end{array}$ & Poesía & Kitty O’Meara & 2020 \\
\hline Repatriación & Poesía & $\begin{array}{l}\text { Joaquín Pérez } \\
\text { Azaústre }\end{array}$ & 2020 \\
\hline Haikus & Poesía & Fernando Beltrán & 2020 \\
\hline Un país enfermo & Poesía & $\begin{array}{l}\text { Cesar Antonio } \\
\text { Molina }\end{array}$ & 2020 \\
\hline Corona de amor & Poesía & Clara Janés & 2020 \\
\hline $\begin{array}{l}\text { Coronavirus. Historias reales en primera línea } \\
\text { de batalla }\end{array}$ & Testimonial & Ana Polegre & 2021 \\
\hline Dioses con pies de barro & Divulgación & Jordi Serrallonga & 2021 \\
\hline Diario de la alarma & Testimonial & Lorenzo Silva & 2021 \\
\hline Cambiemos de vía & Ensayo & Edgar Morin & 2021 \\
\hline $\begin{array}{l}\text { Preparados para la próxima pandemia. } \\
\text { Reflexiones desde la ciencia }\end{array}$ & Ensayo & $\begin{array}{l}\text { Ignacio López- } \\
\text { Goñi }\end{array}$ & 2021 \\
\hline $\begin{array}{l}\text { En primera línea. Un testimonio desde la UCI de } \\
\text { la crisis del coronavirus }\end{array}$ & Testimonial & Gabriel Heras & 2021 \\
\hline $\begin{array}{l}\text { Virus. La guerra de los mil millones de años. Por qué } \\
\text { los humanos somos presa fácil de las } \\
\text { pandemias }\end{array}$ & Divulgación & $\begin{array}{l}\text { Juan Botas. J.J. Gómez } \\
\text { Cadenas }\end{array}$ & 2021 \\
\hline $\begin{array}{l}\text { El enemigo invisible. La historia secreta de los } \\
\text { virus }\end{array}$ & Divulgación & $\begin{array}{l}\text { Dorothy } \mathrm{H} \text {. } \\
\text { Crawford }\end{array}$ & 2021 \\
\hline $\begin{array}{l}\text { Los días de la fiebre. Corea del Sur, el país que } \\
\text { desafió al virus }\end{array}$ & Testimonial & $\begin{array}{l}\text { Andrés Felipe } \\
\text { Solano Mendoza }\end{array}$ & 2021 \\
\hline $\begin{array}{l}\text { Pandemia: virus y miedo. Una historia desde la } \\
\text { gripe española hasta el coronavirus Covid-19 }\end{array}$ & Divulgación & Mónica Müller & 2021 \\
\hline $\begin{array}{l}\text { La amenaza más letal. Nuestra guerra contra } \\
\text { las pandemias y cómo evitar la próxima }\end{array}$ & Divulgación & $\begin{array}{l}\text { Michael T. } \\
\text { Osterholm }\end{array}$ & 2021 \\
\hline $\begin{array}{l}\text { No tocar. Ciencia contra la desinformación en la } \\
\text { pandemia de Covid-19 }\end{array}$ & Divulgación & $\begin{array}{l}\text { Deborah García } \\
\text { Bello }\end{array}$ & 2021 \\
\hline Los abrazos perdidos & Cuento & $\begin{array}{l}\text { Nayara Granados. } \\
\text { Leire Salaberria }\end{array}$ & 2021 \\
\hline Pandemiah & Cómic. & Mercrominah & 2021 \\
\hline Sinué el egipcio & Novela & Mika Waltari & 1945 \\
\hline
\end{tabular}

Rev. Med. Cine. 2021; 17 (4), 315-335 Ediciones Universidad de Salamanca / @@@ J. Med. Mov., 2021; 17 (4), 315-335 


\section{SIMILITUDES Y DIFERENCIAS ENTRE EL DIARIO DEL AÑO DE LA PESTE \\ Y LA ENFERMEDAD POR COVID-19}

SARA DE ARRIBA IGLESIAS; AGUSTÍN HIDALGO BALSERA

\begin{tabular}{|l|l|l|l|}
\hline TÍTULO & GÉNERO & AUTOR & AÑO \\
\hline El origen del hombre & Divulgación & Charles Darwin & 1871 \\
\hline $\begin{array}{l}\text { El mapa fantasma. La epidemia que cambió la } \\
\text { ciencia, las ciudades y el mundo moderno. }\end{array}$ & Divulgación & Steven Johnson & 2020 \\
\hline $\begin{array}{l}\text { Covid-19. La catástrofe. Qué hicimos mal y cómo } \\
\text { impedir que vuelva a suceder }\end{array}$ & Ensayo & Richard Horton & 2021 \\
\hline
\end{tabular}

enfermedades a las que se pueden aplicar estor términos, se debe hacer utilizando denominaciones arbitrarias, como uno, dos, tres" ${ }^{6}$; y e) por último, y sirviendo este compendio de base para comparar posteriormente con los elementos presentes en el Diario, hay que tener en cuenta un hecho excepcional acerca de las epidemias en la literatura por el cual lo social, lo colectivo, trasciende a lo particular.

\section{Características generales de las epidemias}

Para Hipócrates, que fue el primero en aplicar el concepto a la medicina, una epidemia era "todos aquellos síntomas experimentados en un lugar determinado en un periodo dado de tiempo durante el que su población estaba aquejada por la enfermedad. En tales circunstancias, no distinguía entre distintas enfermedades. Posteriormente, el término epidemia se llegó a asociar con una enfermedad, luego con un microbio y después con una cepa microbiana, pero este proceso de refinamiento no empezó hasta la Edad Media, cuando la gran epidemia de peste obligó a reconsiderarlo» (...) Actualmente, por epidemia se entiende "un aumento, muchas veces súbito, del número de casos de una enfermedad determinada en una población dada. En cambio, una enfermedad endémica es una enfermedad que siempre está presente en esa población $»^{6}$. Este último significado justifica que hoy escuchemos constantemente cómo se les atribuye a enfermedades como la obesidad, el cáncer o la diabetes la categoría de "epidemias» del siglo $\mathrm{XXI}^{7}$. Por desgracia, hasta hace poco desconocíamos que el sentido más literal del término tendría tanta repercusión en nuestro presente.

El objetivo general del trabajo es analizar la obra de Daniel Defoe El Diario del año de la peste, ambientada en la epidemia de peste ocurrida en Londres en 1665, para conocer la vigencia actual de sus contenidos, explorar la potencial utilidad formativa para los futuros profesionales de la salud y establecer, en la medida de lo posible, paralelismos con lo ocurrido durante la pandemia por COVID-19.

En el análisis de la obra hemos identificado y agrupado los aspectos descritos en tres grandes apartados: a) Nosología de la medicina; b) Sociología de la medicina, y c) Aspectos sociales concurrentes o consecuencia de la epidemia, y se han elegido comparadores para la COVID-19 (Tabla 2). Puntualmente, se ha tenido en cuenta el esquema narrativo de otras epidemias, sobre todo de los relacionados con la pandemia por la denominada Gripe Española ${ }^{6,8}$ para la observación de similitudes y divergencias. Para la discusión hemos contrapuesto la peste negra y la enfermedad por Covid-19 empleando tablas esquemáticas, a partir de las cuales se han señalado estas similitudes y diferencias.

A pesar del género literario de la obra y de que su autor era sólo un niño durante la epidemia de peste que asoló Londres en 1665, podemos confiar en su experiencia narrativa (es también autor de la aclamada Robinson Crusoe, por ejemplo) y en su concienzudo método de trabajo e investigación - ampliamente documentado a partir de obras como Instrucciones necesarias para la prevención y la cura de la peste (1665), Medela Pestilentia 


\section{SIMILITUDES Y DIFERENCIAS ENTRE EL DIARIO DEL AÑO DE LA PESTE \\ Y LA ENFERMEDAD POR COVID-19 \\ SARA DE ARRIBA IGLESIAS; AGUSTÍN HIDALGO BALSERA}

Tabla 2. Aspectos analizados en el Diario del año de la Peste y comparadores utilizados.

\begin{tabular}{|c|c|}
\hline Nosología de la Medicina & Aspectos sociales asociados a la epidemia \\
\hline $\begin{array}{l}\checkmark \text { Origen y causa de la enfermedad. } \\
\checkmark \text { Mecanismos de transmisión. } \\
\checkmark \text { Medidas de control. } \\
\checkmark \text { Cómo se manifiesta: signos y síntomas. } \\
\checkmark \text { Terapéutica: “Remedios” preventivos y tratamientos. } \\
\checkmark \text { Epidemiología y Salud Pública: causas predisponentes } \\
\text { (pobreza, hacinamiento, costumbres disolutas), } \\
\text { medidas de control poblacional, tasas de morbilidad } \\
\text { y mortalidad. } \\
\checkmark \text { Evolución de la enfermedad. } \\
\checkmark \text { Extinción de la enfermedad epidémica. }\end{array}$ & $\begin{array}{l}\checkmark \text { Comportamiento de los ciudadanos: aceptación, } \\
\text { elusión, vandalismo, robo. } \\
\checkmark \text { Aspectos psicológicos del confinamiento, perjuicios } \\
\text { causados por el mismo y estrategias de evasión. } \\
\checkmark \text { Críticas a la clausura de las casas (aumento del } \\
\text { número de defunciones). } \\
\checkmark \text { Organización de funerales y enterramientos. } \\
\checkmark \text { Repercusiones laborales: paro y hambre. } \\
\checkmark \text { Afectación del comercio exterior. }\end{array}$ \\
\hline Sociología de la Medicina & Comparadores COVID-19 \\
\hline $\begin{array}{l}\checkmark \text { Sistemas sanitarios. } \\
\checkmark \text { Organización de la asistencia sanitaria. } \\
\checkmark \text { Medidas adoptadas y respuestas a las mismas. } \\
\checkmark \text { Demografía sanitaria: médicos y otro personal } \\
\text { sanitario que se cita en el texto. } \\
\checkmark \text { Acceso a cuidados. } \\
\checkmark \text { Hospitales. }\end{array}$ & $\begin{array}{l}\checkmark \text { Estudios y artículos en revistas y páginas web } \\
\text { especializadas (PubMed, Cochrane, The Lancet, } \\
\text { Revista. Medicina y Cine.) } \\
\checkmark \text { Datos sobre COVID-19 procedentes de organismos } \\
\text { oficiales. } \\
\checkmark \text { Fuentes de Información histórica } \\
\checkmark \text { Artículos de opinión de científicos, escritores, } \\
\text { sociólogos, periodistas etc. }\end{array}$ \\
\hline
\end{tabular}

(1664), El espantoso azote de Londres(1665), o La voz terrible de Dios en la ciudad (1667)- para exponernos los hechos reales, aunque literaturizados. Asímismo, parece probado que las cifras de muertos semanales y otras estadísticas proceden del London's Dreadful Visitation. Como nos introduce Anthony Burges "La finalidad de la escritura era dejar constancia, con una inmediatez aparentemente descuidada, de hechos verdaderos, y, si los hechos resultaban extraños y sorprendentes, tanto mejor. Hasta cierto punto, los datos podían manipularse levemente, como un fotógrafo de prensa que enseña una hogaza de pan para que unos niños hambrientos parezcan más hambrientos» ${ }^{9}$.

Análisis de la obra. Nosología de la medicina

Origen y causa de la enfermedad

En El diario, el origen de la enfermedad es divino, una especie de castigo ( $« E$ I Señor nos envió este castigo») no especificado pero que asienta en el capricho de los dioses para con los humanos como reconoce buena parte de la literatura clásica ambientada en el mito; esta misma voluntad divina es la responsable de la extinción de la epidemia. Debemos recordar que aún faltaban dos siglos para la identificación de la Yersinia Pestis como el agente causalde la peste bubónica y la identificación del mecanismo concreto de transmisión gracias a la realización del denominado Experimento Karachi por Paul Louis Simond, y su sensibilidad a antibióticos ${ }^{10,11}$. Así mismo, la teoría miasmática fue sustituida por la teoría bacteriana de la enfermedad.

Siglos después, admitimos que la ciencia ha sustituido las interpretaciones míticas, mágicas y religiosas de la enfermedad por explicaciones racionales de base experimental ${ }^{12}$ y que los Estados han sustituido a los dioses como proveedores de auxilio ante la enfermedad. Esto ha facilitado que, en el caso de la COVID-19, haya sido posible, 


\section{SIMILITUDES Y DIFERENCIAS ENTRE EL DIARIO DEL AÑO DE LA PESTE \\ Y LA ENFERMEDAD POR COVID-19 \\ SARA DE ARRIBA IGLESIAS; AGUSTÍN HIDALGO BALSERA}

en un tiempo breve, conocer el agente causal, el virus SARS-CoV-2 de origen zoonótico, su secuencia génica de ARN monocatenario, el intercambio de información entre los científicos, el ensayo de opciones terapéuticas y el diseño y administración de vacunas a la población, en menos de un año desde la declaración de la pandemia.

La obra analizada, de forma similar a Robinson Crusoe, enfrenta al hombre, individual y colectivamente a lo inevitable y lo inesperado. En el caso de El Diario del Año dela Peste utiliza, como elemento desencadenante de las situaciones, la llegada de la peste bubónica a la ciudad de Londres en 1665 siguiendo el esquema clásico de una enfermedad epidémica, mortal, que llega a través de la principal vía de comunicación que son los puertos de mar de la época, del extranjero, de Holanda o Francia, que tiene un cluster inicial desde el que se extiende. Algo similar ha ocurrido con la pandemia de COVID-19, con su epicentro en la ciudad china de Wuhan, desde la que en poco tiempo se ha extendido, a través de las vías comerciales y el turismo, a todos los continentes.

\section{Mecanismos de transmisión}

Los ciudadanos sabían que se transmitía a través de la respiración, el sudor, el hedor de las llagas de los enfermos... En definitiva, a través de los efluvios, aunque también se tomaban precauciones especiales con la ropa y los enseres que habían estado en contacto con enfermos y se aceptaba que podrían existir además medios de transmisión desconocidos. A medida que la epidemia fue avanzando, surgió un concepto equiparable a nuestros portadores "asintomáticos» de hoy en día, aunque con final fatal en el caso de la peste. Dice Defoe: "Y aquí debo hacer una observación más que puede ser útil a nuestros descendientes, relativa al modo en que se contaminaban los unos a los otros; me refiero a que no eran solo los enfermos los que transmitían la peste a las personas sanas, sino que también los sanos la transmitían. [...] Y esta es la razón de que sea imposible evitar que en una epidemia se extienda la peste, aun tomando todas las precauciones imaginables, pues es imposible distinguir a las personas contaminadas de las sanas, así como que las personas contaminadas se den perfecta cuenta de su estado. ${ }^{9}$

En ambos casos las enfermedades han sido consideradas de declaración obligatoria y, en alguna medida, reconocen factores predisponentes tales como la desigual distribución de la riqueza, las inequidades, la sobrepoblación y el hacinamiento, a lo que se ha unido, en la corriente ambientalista actual, la invocación de las agresiones al medio ambiente, el contacto con la vida animal (no en vano, el $70 \%$ de las enfermedades infecciosas humanas tienen un origen zoonótico), y la escasa consideración a las advertencias de los virólogos que habían advertido de la contingencia de una nueva gran pandemia ${ }^{1,13}$, convencidos de que «El microbio o patógeno, causante de la enfermedad que provocará la siguiente pandemia ya está entre nosotros» ${ }^{7}$.

Como es clásico, la epidemio llega desde fuera, posiblemente desde Holanda o Francia: «Dos hombres, según dijeron franceses, murieron de la peste en Long Acre».

\section{Medidas de control}

Desde el punto de vista de la prevención, los ciudadanos se cuidaban bien de no establecer contacto físico con no convivientes, por ejemplo, cuando iban a hacer la compra. Aunque en una primera versión del distanciamiento social la gente sólo recelaba de los enfermos, en cuanto se supo de la existencia de portadores asintomáticos los londinenses tendieron al auto confinamiento, con buenos resultados. Como se recoge en este fragmento del Diario ${ }^{9}:$ «[...] muchas familias, previendo que se aproximaba aquel desastre, hicieron un acopio de provisiones suficientes para todos, y ellos mismo se encerraron, y de un modo tan efectivo que no volvió a vérseles ni a oírseles hasta que la epidemia hubo 


\section{SIMILITUDES Y DIFERENCIAS ENTRE EL DIARIO DEL AÑO DE LA PESTE \\ Y LA ENFERMEDAD POR COVID-19}

SARA DE ARRIBA IGLESIAS; AGUSTÍN HIDALGO BALSERA

cesado por completo, y entonces volvieron a salir a la calle, sanos y salvos."

Otros centenares se aislaron en barcos a lo largo del río: «diez mil personas o más, se habían puesto (así) a refugio de la violencia de la epidemia, y allí vivían totalmente seguros $" .{ }^{9}$ Además, se ponían ajo y ruda en la boca o fumaban tabaco para espantarlo, y humedecían su ropa, cabello o el pañuelo que se ponían en la boca con vinagre.

Manifestación de la enfermedad: signos y síntomas

El tiempo de incubación, si bien no se precisa exactamente, se limita en no más de dos semanas, siendo los síntomas bastante concretos: malestar general y fiebre alta, "señales fatales» en la piel en forma de manchas negras originadas por gangrena y los famosos y dolorosos bubones, que no eran otra cosa que adenopatías situadas en las inglés, el cuello o las axilas.

El cuadro clínico ha estado bien descrito desde el principio en cada caso, con signos y síntomas patognomónicos, si bien en el caso de la COVID-19 la enfermedad aún está por definir en algunos aspectos moleculares de la patogenia, en la descripción de las patologías crónicas secundarias a la infección y en el abordaje de las mismas. De forma similar, se ha establecido la existencia de contagiados asintomáticos que ha provocado cierta polémica acerca de las estrategias de prevención de la transmisión de la COVID-19 en, por ejemplo, las residencias de ancianos ${ }^{14-16}$,y el período de incubación se ha establecido en 10-15 días. El propio Defoe escribió en su obra:

"un enfermo no creo que pueda estar contaminado hasta el punto de ser peligroso para los demás más de quince o dieciséis días. ${ }^{9}$

En febrero del presente año se publicó una revisión ${ }^{17}$, en la que se indica que la media de la incubación del SARs-CoV-2 está en 7.8 días, lo que encaja con la información proporcionada por la OMS. La mayor parte de los autores proponen una cuarentena de mínimo 14 días. ${ }^{18}$
En el caso de la COVID-19, el diagnóstico, gracias a la evolución tecno-científica, ha sido muy eficiente y, más allá de la constatación de los signos y síntomas clínicos, ha sido posible recurrir a técnicas muy sensibles y específicas como la PCR. ${ }^{19}$

Terapéutica: "Remedios» preventivos y tratamientos

En cuanto al tratamiento de ambas enfermedades, es posible constatar algunas similitudes y, naturalmente, algunas diferencias. Entre las primeras se encuentran las medidas populares sin contraste científico y asentadas, en el mejor de los casos, en la observación de casos precedentes, pero cargadas de componentes mágicos, míticos y religiosos, como también ocurrió en la Gripe Española ${ }^{8}$.

Con respecto a los remedios populares, existían multitud de fórmulas mágicas elaboradas por charlatanes y curanderos, incluyendo pócimas tóxicas que contenían mercurio. Y es que no faltaron falsos médicos que anunciaban remedios milagrosos en las puertas de las casas y las esquinas de las calles. En el caso de que se estableciese la enfermedad, había consenso sobre que los afectados debían meterse en la cama y sudar para expulsarla. El sector médico recomendaba el aislamiento y la cuarentena, así como quemar diferentes sustancias cuando se tuviese que abrir una ventana o una puerta. En esta misma línea, para purificar casas que habían sido contaminadas se quemaban perfumes, incienso, colofonia o azufre en espacios herméticamente cerrados y luego se hacía estallar una gran carga de pólvora.

Las propuestas de prácticas pseudocientíficas no han sido menores en el caso de la COVID-19 donde hasta un Presidente de Gobierno se ha atrevido a recomendar ingesta de lejía como medida profiláctica. El "triunfo» de las pseudociencias se ha visto favorecido por la libertad de expresión en las redes sociales y medios de comunicación de masas.

En nuestra sociedad científica y tecnológica, no han faltado propuestas, incluso basadas en 


\section{SIMILITUDES Y DIFERENCIAS ENTRE EL DIARIO DEL AÑO DE LA PESTE \\ Y LA ENFERMEDAD POR COVID-19 \\ SARA DE ARRIBA IGLESIAS; AGUSTÍN HIDALGO BALSERA}

estudios clínicos inadecuados. Es el caso de los tratamientos con hidroxicloroquina, diferentes antivirales, vitamina $\mathrm{D}$, etc. ${ }^{20}$

Los tratamientos propiamente dichos eran escasos, y se basaban en sajar los bubones o aplicar cáusticos sobre los mismos, ya que al parecer si éstos se curaban los pacientes sobrevivían.

Además, los médicos desarrollaron la píldora antipestilencial o "pill ruff», compuesta por los mismos ingredientes en diferentes proporciones según el criterio y la experiencia del profesional que la preparase.

Respecto al tratamiento médico las recomendaciones generales (higiene, confinamiento, aislamiento) se parecen en ambos casos, así como las medidas iniciales, ya que tanto el empleo de la pill ruff o el hecho de intentar eliminar los bubones como el uso de hidroxicloroquina, remdesivir o interferón se aplicaron de manera empírica. El mayor salto diferencial y cualitativo aquí lo constituyen el uso de los corticoides y el desarrollo de las vacunas, consecuencia de la cantidad de recursos humanos y económicos que se están dedicando al tema. Por otra parte, La pandemia ha supuesto un cambio en los modelos de investigación a nivel global, poniendo de relieve las carencias del sistema actual. Como se explica en algunos artículos $^{21}$ la gran presión sobre investigadores y políticos para encontrar soluciones de manera casi inmediata ha dejado clara la importancia de desarrollar ensayos clínicos randomizados de calidad, así como de diseñar ensayos a largo plazo siguiendo protocolos adecuados.

\section{Epidemiología y Salud Pública}

La ciudad había aumentado su población a expensas de trabajadores humildes, esto condicionó masas de pobres, falta de viviendas y hacinamiento de la población en los barrios. De hecho, la epidemia empezó en barrios extramuros y se extendió hacia el este. Concretamente, en la parroquia de Saint Giles hubo dos fallecimientos «sospechosos» en 1664, otro en febrero de 1665 y uno más en abril, si bien la causa de la muerte no se atribuyó a la peste hasta principios de mayo. La peste alcanzó el punto más alto de la curva de mortalidad en el mes de septiembre, en el que se registraron más de 7000 muertes por semana. Esta mortalidad de la peste bubónica del siglo XVII en Londres fue mucho más mortífera ( $25 \%$ de la población) que la COVID-19 a nivel mundial $(0.044 \%)$. Esto probablemente pueda deberse a factores ya comentados, como el hacinamiento, la falta de medidas higiénico sanitarias adecuadas y al avance en los cuidados.

\section{Evolución de la enfermedad}

Las características del avance de la epidemia - a medida que progresaba en una parte, perdía violencia en el resto - permitieron hacer una vida más o menos normal en los barrios en los que no se estaba dando la mayor virulencia. A medida que la epidemia iba cediendo, se describen varios rebrotes meramente transitorios.

\section{Extinción de la enfermedad epidémica}

Los motivos de esta pérdida de virulencia no quedan del todo claros: "En medio de su desgracia, cuando la situación de la ciudad de Londres era verdaderamente tan calamitosa, precisamente plugo a Dios, por decirlo así, desarmar con Su propia mano a este enemigo; se arrebató el veneno al aguijón. Fue algo portentoso; incluso los mismos médicos quedaron asombrados»"; la desaparición de la COVID-19, ya podemos adelantarla: se producirá por la inmunización masiva de la población.

La tabla 3 recoge aspectos comparativos sobre nosología de la medicina entre El Diario y la COVID-19.

\section{Sociología de la medicina}

\section{Sistemas sanitarios}

Si bien la asistencia sanitaria de la época se caracterizaba por el ejercicio liberal de la profesión de médico en la que los ciudadanos se hacían 


\section{SIMILITUDES Y DIFERENCIAS ENTRE EL DIARIO DEL AÑO DE LA PESTE \\ Y LA ENFERMEDAD POR COVID-19 \\ SARA DE ARRIBA IGLESIAS; AGUSTÍN HIDALGO BALSERA}

Tabla 3. Algunas relaciones tentativas entre aspectos nosológicos de la epidemia de cólera de Londres descrita en El diario del año de la peste y durante la COVID-19.

\begin{tabular}{|c|c|c|}
\hline NOSOLOGÍA MÉDICA & DIARIO DEL AÑO DE LA PESTE & ENFERMEDAD POR COVID-19 \\
\hline CAUSA & Castigo divino. & $\begin{array}{l}\text { Coronavirus de tipo } 2 \text { causante del } \\
\text { síndrome respiratorio agudo severo (SRAS- } \\
\text { CoV-2). }\end{array}$ \\
\hline INCUBACIÓN & $\begin{array}{l}\text { Inespecífico (no más de 15/16 días).Hay } \\
\text { casos de evolución en horas. }\end{array}$ & Entre 1-14 días. \\
\hline TRANSMISIÓN & $\begin{array}{l}\text { - Efluvios de los enfermos o } \\
\text { asintomáticos. } \\
\text { - Objetos contaminados. }\end{array}$ & $\begin{array}{l}\text { - Gotículas respiratorias. } \\
\text { - No frecuente a través de objetos si } \\
\text { buena desinfección. }\end{array}$ \\
\hline SIGNOS Y SÍNTOMAS & $\begin{array}{l}\text { - Manchas negras en la piel. } \\
\text { - Bubones. } \\
\text { - Malestar (vómitos, cefalea). } \\
\text { - Fiebre alta (delirios). } \\
\text { - Asintomáticos que se desvanecían y } \\
\quad \text { morían repentinamente. }\end{array}$ & $\begin{array}{l}\text { - HABITUALES: fiebre, tos seca, astenia. } \\
\text { - OTROS: anosmia/ageusia, congestión } \\
\text { nasal conjuntivitis, cefalea, náuseas o } \\
\text { vómitos, diarrea,... } \\
\text { - } \text { GRAVES: disnea, pérdida de apetito, } \\
\text { confusión, fiebre > } 38\end{array}$ \\
\hline DIAGNÓSTICO & $\begin{array}{l}\text { - Objetivación de signos y síntomas. } \\
\text { - Olor del aliento. } \\
\text { - Soplar en un cristal. }\end{array}$ & $\begin{array}{l}\text { - Historia Clínica sugerente; PCR. } \\
\text { - Prueba rápida de antígenos (más } \\
\text { rápidas, menos precisas). } \\
\text { - Pruebas de anticuerpos (infección } \\
\text { pasada). }\end{array}$ \\
\hline $\begin{array}{l}\text { TRANSMISIÓN VERTICAL } \\
\text { EN EL EMBARAZO }\end{array}$ & Transmisión a través de la leche. & No hay evidencia científica por el momento. \\
\hline $\begin{array}{l}\text { REMEDIOS POPULARES } \\
\text { (Poco o nada eficaces) }\end{array}$ & $\begin{array}{l}\text { - Preventivos varios y fórmulas } \\
\text { mágicas elaboradas por charlatanes y } \\
\text { curanderos. } \\
\text { - "Sudar". } \\
\text { - Mantener distancia social. } \\
\text { - Encender fuegos públicos } \\
\text { - Sustancias aromáticas }\end{array}$ & $\begin{array}{l}\text { - Suplementos alimenticios. } \\
\text { - Comer ajo o chiles. } \\
\text { - Beber lejía, metanol o etanol. } \\
\text { - Desinfectar la piel con radiación UV. } \\
\text { - MMS (clorito de sodio). } \\
\text { - Propuestas pseudocientíficas. }\end{array}$ \\
\hline $\begin{array}{l}\text { RECOMENDACIONES } \\
\text { MÉDICAS/TTOS. } \\
\text { MÉDICOS }\end{array}$ & $\begin{array}{l}\text { - Aislamiento + quemar sustancias. } \\
\text { - Sajar los bubones. } \\
\text { - Caústicos sobre los bubones. } \\
\text { - Pill ruff. }\end{array}$ & $\begin{array}{l}\text { - TRATAMIENTOS: soporte respiratorio, } \\
\text { dexametasona, VACUNAS. } \\
\text { - } \text { RECOMENDACIONES: distancia } \\
\text { social, mascarillas, lavado de manos, } \\
\text { ventilación de espacios cerrados. }\end{array}$ \\
\hline CIFRAS DEFUNCIONES & $\begin{array}{l}\text { Del 20-12-64 al 19-12-65: } 68596 \\
\text { muertes. } \\
\text { Población total en torno a } 400.000 \\
\text { Tasa de mortalidad: aproximadamente } \\
\text { el } 25 \% .\end{array}$ & $\begin{array}{l}\text { Más de } 3 \text { millones en todo el mundo. } \\
\text { Población mundial: } 7.800 \text { millones Tasa de } \\
\text { mortalidad de } 0.044 \text {. }\end{array}$ \\
\hline $\begin{array}{l}\text { DECLARACIÓN } \\
\text { OBLIGATORIA }\end{array}$ & $\begin{array}{l}\text { - Dentro del plazo de dos horas. } \\
\text { - Se plantea el rastreo como imposible. }\end{array}$ & - Importante labor de los rastreadores. \\
\hline EVOLUCIÓN & $\begin{array}{l}\text { - Se describen varios rebrotes de } \\
\text { peste ya en la fase de remisión de la } \\
\text { epidemia. }\end{array}$ & $\begin{array}{l}\text { - "Evolución en oleadas": cuatro hasta la } \\
\text { fecha de realización de este trabajo. }\end{array}$ \\
\hline
\end{tabular}

Rev. Med. Cine. 2021; 17 (4), 315-335 Ediciones Universidad de Salamanca / @®@@ J. Med. Mov., 2021; 17 (4), 315-335 


\section{SIMILITUDES Y DIFERENCIAS ENTRE EL DIARIO DEL AÑO DE LA PESTE \\ Y LA ENFERMEDAD POR COVID-19}

SARA DE ARRIBA IGLESIAS; AGUSTÍN HIDALGO BALSERA

visitar según su poder adquisitivo, durante la epidemia se crearon "hospitales de apestados» y se facultó a personal "paramédico» auxiliar con funciones concretas como los inspectores, los asistentes de enfermo y las inquiridoras.

\section{Organización de la asistencia sanitaria}

La peste era una enfermedad de declaración obligatoria, ya que según las ordenanzas públicas «los cabezas de familia estaban obligados a informar al inspector de su demarcación de la existencia de un afectado en la familia dentro de las dos horas posteriores a conocerse la fatal noticia». ${ }^{9}$

La notificación obligatoria iba seguida de la clausura de las casas contaminadas a través de los alguaciles y por orden de los inspectores. Se clausuraba la casa del enfermo (con toda su familia incluida, aunque estuviese sana) durante el tiempo que durase la enfermedad más un mínimo de un mes a partir de que desapareciesen los últimos síntomas del mal.

Durante este tiempo, las casas tenían que estar marcadas con una cruz roja y el letrero: «Señor, ten piedad de nosotros.» (Foto 1)

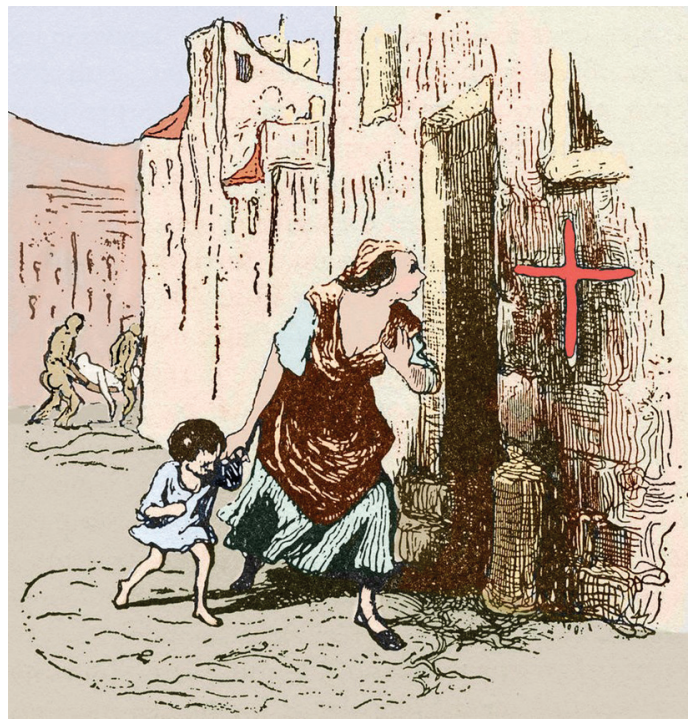

Foto 1. Señalización de las casas contaminadas. Disponible en: bbc.es
Medidas adoptadas y respuestas a las mismas

Las medidas se publicaron en forma de ordenanzas, y contemplaban todos los aspectos de interés en relación con la epidemia. Más allá de la clausura, se especificaba cómo había que desinfectar los efectos domésticos, y se prohibía mudarse salvo al hospital, la segunda residencia o una tienda de campaña fuera de Londres, teniendo que hacerse el traslado siempre de noche y sin mezclar sanos con enfermos. Y «si un conviviente sano tenía que trasladarse, era obligatorio que contase con un certificado de salud expedido por un magistrado» ${ }^{9}$ (concretamente, por un juez de paz). El paralelismo con la situación actual es grande.

También se dictaron medidas concretas sobre la higiene, salubridad y gestión de los desechos o sobre la desinfección de coches de alquiler y establecimientos públicos. Se prohibió la tenencia de animales domésticos (cerdos, perros, gatos o palomas) y se ordenó darles muerte, por miedo a que pudiesen actuar como vectores o transmisores de la enfermedad. También se prohibió la libre circulación de los mendigos y, hacia el final de la epidemia, se encendieron fuegos públicos para purificar el aire (Foto 2)

Las medidas públicas, han sido aplicadas por la autoridad competente en cada caso, el Lord Alcalde de la ciudad de Londres y, en nuestro país, el Consejo de Ministros con el respaldo del Parlamento y/o de los jueces según las fases de la pandemia. Estas autoridades (o las Comunidades Autónomas) han ejercido la macrogestión (política sanitaria) sanitaria a nivel de todo el Estado. En ambos casos, también, se ha tratado de establecer unas normas más o menos claras y de designar unas figuras públicas que se encargan de hacer efectivo su cumplimiento. También, de forma común, es notorio que se adoptaron medidas con un elevado nivel de incertidumbre, incluso en nuestra tecnificada sociedad del siglo XXI, debido a los déficits cognitivos respecto a diferentes aspectos de la pandemia ${ }^{22}$. 


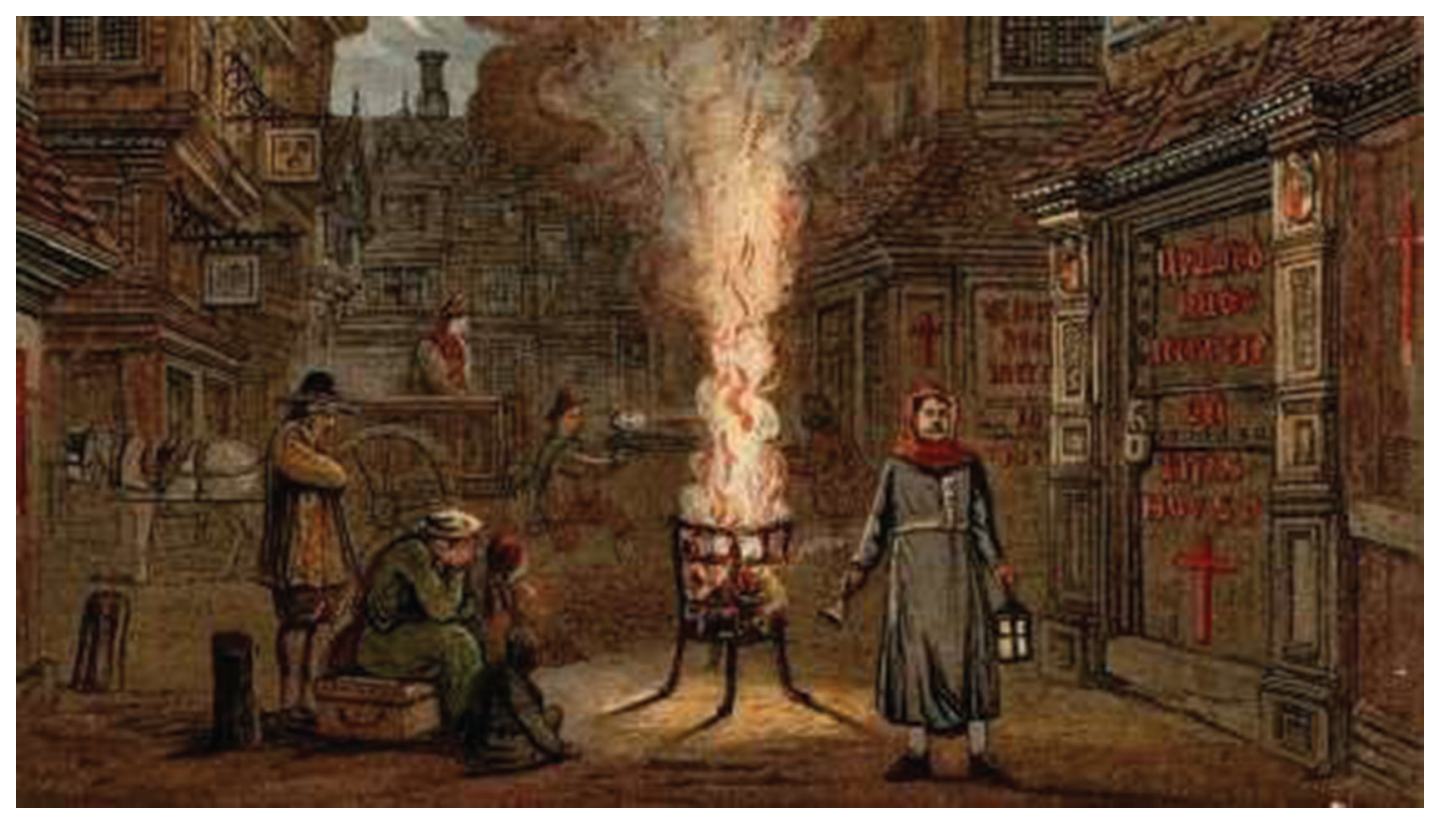

Foto 2. Representación de los fuegos públicos, alguacil, carro de los muertos y señales en las casas clausuradas. Disponible en bbc.es.

Una queja reiterada respecto a la adopción de las medidas por el poder ejecutivo es que "La actual pandemia supone un fracaso de la gobernanza mundial de proporciones inimaginables. La tendencia casi instintiva de la clase dirigente a escudar su responsabilidad en los expertos resulta obscena» ${ }^{23}$.

Dentro de las medidas públicas, adquirió notoriedad en ambos casos, el confinamiento y las limitaciones de las actividades laborales y de ocio. Estas últimas ya son reseñadas en El Diario "Que todo banquete, y particularmente los de las corporaciones de esta ciudad, y comidas en tabernas, cervecerías y otros lugares públicos de reunión queden prohibidos hasta nueva orden; y que el dinero que de otro modo se hubiera empleado en tales cosas se destine a la asistencia de los pobres contaminados por la epidemia» ${ }^{9}$

En ocasiones, en el caso de la pandemia por COVID-19, estas limitaciones se han interpretado como limitaciones de derechos fundamentales. No obstante, en estas situaciones, como recuerda
Benigno Pendás, Catedrático y académico de la Academia de Ciencias Morales y Políticas:

"Los derechos fundamentales sufren también con las crisis sanitarias. Las libertades públicas pueden ceder transitoriamente ante la situación excepcional, pero sólo para la salvaguarda de la vida y la salud» ${ }^{24}$.

También se ha apuntado por otros autores que esta reclusión extrema debe servir para: «repensar el modelo» ${ }^{25}$.

Por último, "todo lo relacionado con la cultura y los espectáculos fue totalmente prohibido, siendo castigados los transgresores», otro aspecto común con la COVID-19. Así mismo, en el Diario se insiste mucho en la imprevisión, tanto por parte de la clase dirigente (se insinúa que en un principio hubo un gran interés por minimizar el impacto de la epidemia, lo que propició la tardanza en la toma de decisiones y la publicación de las ordenanzas y la falta de acopio de víveres, por ejemplo) como de la popular. 


\section{SIMILITUDES Y DIFERENCIAS ENTRE EL DIARIO DEL AÑO DE LA PESTE \\ Y LA ENFERMEDAD POR COVID-19 \\ SARA DE ARRIBA IGLESIAS; AGUSTÍN HIDALGO BALSERA}

\section{Demografía sanitaria. Médicos y otro perso- nal sanitario que se cita en el texto}

Sobre el papel de los médicos y cirujanos, el Colegio de Médicos se encargaba de publicar indicaciones, destinadas sobre todo a promover el uso de medicinas poco costosas para el cuidado de los sectores más pobres de la sociedad. Precisamente éstos, fundamentalmente por falta de recursos que les obligaban a correr más riesgos, pero también por una cierta falta de entendimiento, eran en general peores cumplidores de las medidas públicas.

"-Pero, ¿qué otra cosa puedo hacer? No puedo morirme de hambre. Tanto da coger la peste como morir de hambre. ${ }^{9}$.

Aunque eran pocos los profesionales de la salud que, conscientes de la gravedad del peligro, se mostraban dispuestos a visitar las casas de los enfermos, el Diario cuenta cómo varios de los médicos y cirujanos más eminentes de la ciudad murieron, aún «con los preventivos en la boca». En general, a lo largo de la obra se ensalza su labor.

Cirujanos e inquiridores certificaban la causa de las muertes, $y$ todos estos profesionales y los sepultureros debían ir marcados con una vara de color rojo y acceder solamente a su casa o a la que tuviesen asignada.

El papel de los profesionales de la salud es similar en cuanto a la abnegación de la mayoría por cumplir con los requerimientos de su profesión, si bien en el contexto de la peste esto tenía un componente "obligatorio" y se describe cómo algunos médicos eran reticentes a visitar a los enfermos por puro miedo, realidad comprensible en el contexto de la falta de recursos para protegerse a sí mismos. Por otra parte, el contexto de la pandemia por COVID-19 ha supuesto un desafío en muchos aspectos, exigiendo un sobreesfuerzo a los sistemas de salud y obligando al sistema educativo a reinventarse sobre la marcha, sin guías ni medios excepcionales ${ }^{26}$, lo que ha llevado a algunos autores a plantear que más que una crisis viral estemos viviendo el fin de una época ${ }^{27}$.

La narrativa metafórica eminentemente bélica de los medios de comunicación ${ }^{4}$ los ha pintado generalmente como héroes, representación en un principio muy aceptada y aplaudida por la población pero que no ha tenido correlación con las medidas políticas y las condiciones laborales para con este sector, víctima de un burnout sin precedentes. A este respecto Juan Fueyo sostiene en Viral:

"Los héroes trabajan y mueren agotados en los hospitales. $Y$, en muchas ocasiones, su trabajo y su valor quedan sin recompensa. La sociedad no está compuesta de admiradores y agradecidos, sino de ciegos egoístas» ${ }^{1}$

En reconocimiento a la labor abnegada de los profesionales sanitarios se les concedió el Premio Princesa de Asturias 2020.

\section{Acceso a Cuidados}

Era universal. Toda casa clausurada contaba con guardianes las 24 horas del día, que se encargaban de proporcionar a las familias que no podían salir lo que necesitasen. En el interior de las casas esta misión la cumplirían las asistentas de enfermos.

\section{Hospitales}

La infraestructura pública contaba con dos hospitales específicos para los apestados, si bien en ellos sólo se admitía a quien pudiese pagar los cuidados que allí se dispensaban. Su calidad asistencial era excepcional, pues a pesar de la virulencia del mal, sólo se registraron 315 decesos entre ambos.

Con respecto al tema de los hospitales, probablemente no pueda abordarse de manera global más allá de la saturación y la falta de recursos médicos y humanos, ya que no todos los países lo han tratado de la misma manera. En el caso de España, hemos vivido la creación de hospitales de campaña y hasta la construcción de nuevos espacios, cuya efectividad e implicaciones desde 


\section{SIMILITUDES Y DIFERENCIAS ENTRE EL DIARIO DEL AÑO DE LA PESTE \\ Y LA ENFERMEDAD POR COVID-19 \\ SARA DE ARRIBA IGLESIAS; AGUSTÍN HIDALGO BALSERA}

el punto de vista político y social podrían ser -y de hecho han sido- objeto de amplio debate y arma arrojadiza entre partidos políticos como han ilustrado, día tras día, los medios de comunicación. Un ejemplo del agobio sufrido a nivel hospitalario lo encontramos en el artículo «Viviendo una pandemia ${ }^{28}$, en el que miembros del Servicio de Microbiología del HUCA describen el desconcierto inicial, el aumento exponencial en la carga de trabajo a partir de marzo y cómo fue la adaptación a la nueva normalidad en su laboratorio, con aproximadamente 160000 PCR realizadas en los primeros seis meses de Estado de Alarma.

En la Tabla 4 hemos incluido los aspectos relacionados con la Sociología de la Medicina en El Diario y en la COVID-19

Tabla 4. Algunas relaciones tentativas entre aspectos de Sociología de la Medicina durante la epidemia de cólera de Londres descrita en El diario del año de la peste y durante la COVID-19.

\begin{tabular}{|c|c|c|}
\hline $\begin{array}{l}\text { SOCIOLOGÍA DE LA } \\
\text { MEDICINA }\end{array}$ & DIARIO DEL AÑO DE LA PESTE & ENFERMEDAD POR COVID 19 \\
\hline $\begin{array}{l}\text { DISTRIBUCIÓN DE LA } \\
\text { POBLACIÓN/AVANCE DE LA } \\
\text { EPIDEMIA }\end{array}$ & $\begin{aligned} & \text { - } \text { Superpoblación. } \\
& \text { - } \text { Comienzo de la epidemia } \\
& \text { en el oeste, extendiéndose } \\
& \text { progresivamente hacia el este. } \\
& \text { - Éxodo rural. } \\
& \text { - } \\
& \text { Pobreza. }\end{aligned}$ & $\begin{array}{l}\text { - Mayor transmisión en ambientes cerrados, } \\
\text { sin recursos de protección, con alta } \\
\text { densidad de población, trabajadores de } \\
\text { primera línea en diferentes sectores y con } \\
\text { baja posibilidad de movilidad. }\end{array}$ \\
\hline HOSPITALES & $\begin{array}{l}\text { - Dos hospitales de apestados } \\
\text { "privados". } \\
\text { - Mortandad escasa. }\end{array}$ & $\begin{array}{l}\text { - Saturación del Sistema Nacional de Salud. } \\
\text { - Hospitales de campaña. } \\
\text { - Construcción de nuevos hospitales. }\end{array}$ \\
\hline $\begin{array}{l}\text { MEDIDAS PÚBLICAS: } \\
\text { ORDENANZAS }\end{array}$ & $\begin{array}{l}\text { - Designación de figuras públicas y } \\
\text { determinación de sus labores. } \\
\text { - Reclusión de los enfermos. } \\
\text { - Desinfección de efectos } \\
\text { domésticos. } \\
\text { - Clausura de casas. } \\
\text { - Restricciones de movilidad. } \\
\text { - Recomendaciones para los } \\
\text { - habitantes. } \\
\text { - Salud pública } \\
\text { - Mendigos. } \\
\text { - Cultura y vida social. }\end{array}$ & $\begin{array}{l}\text { - Estado de alarma y prórrogas. } \\
\text { - Transición hacia una nueva normalidad. } \\
\text { - Medidas de gestión de la crisis sanitaria: } \\
\text { sanitarias, seguridad, transporte y } \\
\text { movilidad, defensa, económicas, otras. }\end{array}$ \\
\hline $\begin{array}{l}\text { PAPEL DE LOS MÉDICOS Y } \\
\text { CIRUJANOS }\end{array}$ & $\begin{array}{l}\text { - Colegio de Médicos publicaba } \\
\text { indicaciones. } \\
\text { - Contagios y muertes. } \\
\text { - Reticencia a desarrollar su labor. }\end{array}$ & $\begin{array}{l}\text { - Falta de medios. } \\
\text { - Burnout. }\end{array}$ \\
\hline IMPREVISIÓN & $\begin{array}{l}\text { - No se hizo acopio de lo necesario } \\
\text { para que la gente pudiese } \\
\text { aislarse en casa. } \\
\text { - Poca previsión también en } \\
\text { cuanto a las ordenanzas públicas. }\end{array}$ & $\begin{array}{l}\text { - Ausencia de un anuncio temprano de la } \\
\text { gravedad potencial de la situación tanto en } \\
\text { la Unión Europea como en España. } \\
\text { - Imprevisión } \\
\text { - Gestión en situación de gran } \\
\text { incertidumbre. }\end{array}$ \\
\hline
\end{tabular}

Rev. Med. Cine. 2021; 17 (4), 315-335 Ediciones Universidad de Salamanca / @®@ J. Med. Mov., 2021; 17 (4), $315-335$ [ 328 ] 


\section{SIMILITUDES Y DIFERENCIAS ENTRE EL DIARIO DEL AÑO DE LA PESTE \\ Y LA ENFERMEDAD POR COVID-19}

SARA DE ARRIBA IGLESIAS; AGUSTÍN HIDALGO BALSERA

Aspectos sociales concurrentes y/o consecuencias de la epidemia y de las medidas adoptadas

\section{Comportamiento de los ciudadanos}

Aquí podemos encontrar tanta heterogeneidad como en la composición misma de la sociedad. Por una parte, la responsabilidad social de los londinenses se hizo patente en la vacuidad de sus calles, así como en una suerte de sentir general que hacía que, ante una mayor proximidad de la muerte, se "reconciliasen los hombres de buenos principios ${ }^{9}$. En el otro extremo, el pillaje y el vandalismo estaban a la orden del día, en forma de desvalijamiento de establecimientos que habían quedado desprotegidos por emigración o confinamiento de sus dueños, así como de asaltos a las casas desiertas.

Algo que no nos es ajeno en absoluto, son las argucias desarrolladas por los ciudadanos para eludir la clausura de sus domicilios. Éstos despistaban a los guardianes de sus entradas para salir por la puerta trasera, los mandaban a hacer un recado lejos y en su ausencia desatornillaban la cerradura o se descolgaban por el tejado y toda una suerte de triquiñuelas semejantes nacidas de la desesperación.

Puede decirse que los ciudadanos se han comportado de forma responsable en ambas epidemias, posiblemente por una conciencia de ser social y diferentes mecanismos de reacción frente al trauma colectivo. En todo caso, "el afán de ser siempre positivos se vuelve negativo cuando enmascara el dolor, la tristeza o el enfado ${ }^{29}$, sentimientos lógicos ante la situación y que según los estudios sobre salud mental recopilados ${ }^{30-34}$ ha experimentado un gran porcentaje de la población a lo largo del confinamiento.

Ante esta respuesta, Defoe, optimista, sugiere que "Otro año de peste habría reconciliado a todos; el contacto directo con la muerte o con males que amenazan con ella, habría esfumado la hiel de nuestros caracteres, borrado las animosidades que nos separaban y nos habría hecho ver las cosas con ojos distintos a los de antes ${ }^{9}$. Sin embargo, nuestra realidad es algo más amarga, con tendencia a pensar que «En cuanto el contagio pierde fuerza, volvemos a hacer lo mismo que antes". ${ }^{7}$

En todo caso, la respuesta ciudadana puede estar contaminada de supersticiones y teorías conspiratorias fundadas en tres tipos de causas ${ }^{35}$ : epistemológicas (necesidad del ser humano de conocer la verdad ante un acontecimiento significativo, la fiabilidad de la misma y la capacidad de discriminar entre fuentes de información fiable y dudosa, un claro factor educacional); existenciales (necesidad de sentirse seguro en su entorno y de tener cierto control y poder sobre el mismo); y sociales (necesidad de reafirmación como individuo e impacto sobre la autoestima, en relación con personalidades de tipo narcisista. A esto podrían añadirse también la credulidad genuina de las masas, la necesidad de pertenencia a grupos, el instinto gregario, o la respuesta al miedo colectivo, ante el que "se busca un responsable que ha de pagar por todo". ${ }^{36}$

Un aspecto muy debatido ha girado en torno a las libertades públicas y al derecho a la información: sus fuentes, su forma de distribución, su control, su veracidad o falta de la misma y su empleo como arma o forma de manipulación de la población. En la epidemia de Londres se decidió intervenir algún tipo de información para reducir bulos y fuentes alternativas a la «oficial». En la pandemia por COVID-19, la literatura sobre el tema es inabarcable tanto en libros específicos como en redes sociales como en prensa. A modo de ejemplo, un diario de distribución nacional dedicó más del $70 \%$ de sus páginas al tema ${ }^{37}$.

A su vez, esto ha constituido una fuente constante de debate sobre quién, cómo y qué se estaba contando, generando en la población general hastío, confusión, miedo y enfado. Por otro lado, la propia OMS alertó de la «infodemia» que se estaba desarrollando paralelamente. 


\section{SIMILITUDES Y DIFERENCIAS ENTRE EL DIARIO DEL AÑO DE LA PESTE \\ Y LA ENFERMEDAD POR COVID-19 \\ SARA DE ARRIBA IGLESIAS; AGUSTÍN HIDALGO BALSERA}

Aspectos psicológicos del confinamiento, perjuicios causados por el mismo y estrategias de evasión

El Diario se prodiga en descripciones sobre cómo el pesar y la tristeza, la inquietud y la sensación constante de peligro inminente invaden a los londinenses de la época. Refleja la labilidad emocional de los enfermos y sus familiares, aislados, así como los diferentes estadios que atraviesa el ánimo de la población a medida que se va desarrollando la epidemia.

Desde una primera fase de incredulidad y minimización del impacto a una despreocupación y resignación total, pasando por etapas de mucha preocupación y miedo. "En casi todas las casas se veían lágrimas y se oían lamentos, sobre todo en los primeros tiempos de la epidemia, pues hacia el final los corazones de los hombres estaban tan endurecidos y era tal la costumbre de tener la muerte siempre ante Los ojos, que ni siquiera se preocupaban por la pérdida de sus amigos, esperando que a ellos mismos les llegase su hora de un momento a otro" ". También aparece como remarcable el tema de la autolisis, supuestamente en el marco del delirio febril producido por la propia patología.

\section{Críticas a la clausura de las casas}

La clausura de las casas, fue uno de los motivos de mayor descontento entre la población. El hecho de mezclar a enfermos con sanos (aunque se ofreciese como alternativa trasladar a los primeros a los hospitales en ciertas condiciones) no fue bien recibido y generó muchas de las argucias mencionadas más arriba: "recluir a los sanos en las mismas casas que a los enfermos se consideraba algo horrible, y las protestas de la gente que se veía encerrada de este modo eran muy vivas» pues «muchos de los que murieron en esas tristísimas reclusiones, a pesar de tener un apestado en casa, no habrían caído enfermos de haber gozado de libertad». A todo ello, la justificación era que "se trataba del bien público que justificaba el perjuicio de que causaba a unos cuantos. $\|^{9}$

\section{Organización de funerales y enterramientos}

Puesto que los funerales como tal estaban estrictamente prohibidos, el entierro de los muertos había de hacerse siempre antes de la salida del sol o después de su puesta, sin acompañantes. Las tumbas debían tener un mínimo de seis pies de profundidad. A este respecto es remarcable el tema de las fosas comunes, que al principio contenían entre 50-60 cadáveres y luego tuvieron que hacerse más grandes hasta tener la capacidad de albergar los 200-400 muertos que el «carro de los muertos» transportaba cada semana. También en la COVID-19 quedaron suspendidos los funerales y se colapsaron las funerarias.

\section{Ayudas económicas}

También han sido importantes, tanto en la epidemia de Londres de 1665 como en la pandemia COVID-19, las ayudas sociales puestas en marcha por los responsables políticos del momento. Destaca en el momento actual la implantación de la Renta Mínima Vital en España en mayo de 2020, y los ERTE desde el comienzo de la crisis sanitaria. También es compartida con la época de la peste de Londres, la preocupación por la época post-pandemia. Defoe muestra, como causa de la preocupación, el hecho de que "todas las fuentes de caridad pública habían dejado de manar. La gente creía que los motivos principales de aquella calamidad habían cesado, y dejó de mostrarse generosa; pero los casos particulares seguían siendo realmente patéticos, y la verdad es que la miseria de los pobres era muy grande».9

Las reflexiones de economistas ${ }^{38}$, e intelectuales del momento actual ${ }^{39}$, indican que los ajustes económicos posteriores a la pandemia serán severos, y que, aunque el sistema cuenta con amplios recursos de producción, sólo una ínfima parte se pone al servicio de crear las condiciones que permitan mantener o mejorar un buen estado de salud en la población. Para modificar esto habría que reconstruir la

Rev. Med. Cine. 2021; 17 (4), 315-335 Ediciones Universidad de Salamanca / @®@® J. Med. Mov., 2021; 17 (4), $315-335$ [ 330 ] 


\section{SIMILITUDES Y DIFERENCIAS ENTRE EL DIARIO DEL AÑO DE LA PESTE \\ Y LA ENFERMEDAD POR COVID-19 \\ SARA DE ARRIBA IGLESIAS; AGUSTÍN HIDALGO BALSERA}

economía por completo y aceptar que «la crisis nos enseña que nuestras prioridades estaban equivocadas» ${ }^{39}$.

\section{Repercusiones laborales}

El conjunto de medidas públicas tuvo, por supuesto, un gran impacto a diferentes niveles. La paralización del comercio y la vida social resultó en una miseria generalizada, que mostró sin embargo su cara más dura con los pobres y las familias que vivían de pequeños comercios o de trabajos que dependiesen de la artesanía y el comercio en general (y que constituían el sector más amplio de la población).

Llama la atención el tema de las ayudas sociales, proporcionadas de manera ininterrumpida durante muchas semanas por cristianos pudientes y distribuidas por la autoridad. La situación de necesidad más extrema se dio no obstante cuando la epidemia empezó a mitigarse, ya que había una falsa sensación de «vuelta a la normalidad».

\section{Afectación del comercio}

Con respecto al comercio, a nivel interior prácticamente sólo se mantuvo el sector de la alimentación. En el exterior también fue casi nulo, ya que Francia, Holanda, España o Italia no admitían barcos ingleses ni querían tener tratos con ellos, (sobre todo España e Italia). Tuvieron que pasar muchos meses para que se restableciesen las relaciones normales.

Por último, y dentro de las estrategias de recuperación económica y de reactivación del mercado turístico, se debate en estos días la implementación de un Certificado de Salud o Pasaporte Sanitario que permitiría la libre circulación de personas de forma internacional en el supuesto de que estén vacunados, tengan una prueba diagnóstica negativa o anticuerpos por haber pasado ya la enfermedad, lo que, por otra parte, puede plantear un dilema ético acerca de la privacidad de los datos médicos de los viajeros.

La Tabla 5 recoge aspectos comparativos relacionados con características y comportamientos sociológicos detectados en la población durante los episodios de epidemias descritas en el Diario y observados durante la pandemia actual por COVID-19.

Como aprendizaje global del trabajo podríamos decir que, más allá del disfrute estético y de la constatación de elementos de política sanitaria y práctica clínica que se repiten a través de la historia, compartimos con Juan Fueyo, el siguiente pensamiento expresado en su obra Viral: «Estudiar pandemias pasadas podría ayudar a afrontar la próxima, pero cada una tiene sus propias características. Como comentamos antes, cada virus es diferente e infecta con variable virulencia a distintos grupos de la población, pudiendo ser más grave en niños -como la viruela-, en jóvenes -como la gripe española- o en ancianos -como la COVID19-. Un experto en epidemias ha comentado, sin intentar ser irónico o sarcástico: "si has visto una pandemia, has visto eso ... una pandemia» ${ }^{1}$.

En síntesis, cada epidemia / pandemia es diferente a la precedente y supone nuevos retos nosológicos, de gestión sanitaria y social. Pero también, mantenemos la preocupación de que, como enseña la pandemia por la Gripe Española, "Parece que cien años ha sido un período de tiempo efímero para poner en marcha las herramientas necesarias al objeto de contener de manera eficaz una nueva amenaza impuesta por la naturaleza. Esperemos que, de una vez por todas, la pérdida de múltiples vidas humanas lleve implícita la creación de una conciencia colectiva y de un nuevo paradigma social»». 


\section{SIMILITUDES Y DIFERENCIAS ENTRE EL DIARIO DEL AÑO DE LA PESTE \\ Y LA ENFERMEDAD POR COVID-19 \\ SARA DE ARRIBA IGLESIAS; AGUSTÍN HIDALGO BALSERA}

Tabla 5. Algunas relaciones tentativas entre aspectos de Sociología de la Medicina durante la epidemia de cólera de Londres descrita en El diario del año de la peste y durante la COVID-19.

\begin{tabular}{|c|c|c|}
\hline $\begin{array}{l}\text { SOCIOLOGÍA DE LA } \\
\text { MEDICINA }\end{array}$ & DIARIO DEL AÑO DE LA PESTE & ENFERMEDAD POR COVID 19 \\
\hline $\begin{array}{l}\text { SUPERSTICIONES } \\
\text { Y TEORÍAS DE LA } \\
\text { CONSPIRACIÓN }\end{array}$ & $\begin{array}{l}\text { - Cometas como presagio. } \\
\text { - Libros terroríficos. } \\
\text { - Interpretación de sueños por parte de } \\
\text { las comadres. } \\
\text { - Astrólogos, oráculos y embaucadores. } \\
\text { - Pseudociencias }\end{array}$ & $\begin{array}{l}\text { - Negacionismo. } \\
\text { - } 5 \text { G. } \\
\text { - Microchip. } \\
\text { - Diseminación deliberada del virus. } \\
\text { - Pseudociencias }\end{array}$ \\
\hline INFORMACIÓN & Falta de lucha contra la desinformación. & $\begin{array}{l}\text { - Papel de los medios de comunicación: } \\
\text { - Redes Sociales, prensa, radio, televisión. }\end{array}$ \\
\hline $\begin{array}{l}\text { RESPONSABILIDAD } \\
\text { SOCIAL }\end{array}$ & $\begin{array}{l}\text { - Calles vacías. } \\
\text { - Cierta solidaridad colectiva. }\end{array}$ & $\begin{array}{l}\text { "Todo va a salir bien". } \\
\text { - } \quad \text { Respeto masivo a las ordenanzas y } \\
\text { decretos. } \\
\text { - } \quad \text { Algunas medidas coercitivas: sanciones. }\end{array}$ \\
\hline $\begin{array}{l}\text { AYUDAS SOCIALES Y } \\
\text { MISERIA }\end{array}$ & $\begin{array}{l}\text { - Pobres/familias que antes vivían de } \\
\text { su trabajo o de pequeños comercios } \\
\text { tenían que vivir de limosnas. } \\
\text { - Caridad cristiana de los ricos sin } \\
\text { interrupción durante muchas } \\
\text { semanas. } \\
\text { - Pobres peores cumplidores de las } \\
\text { medidas en general, por falta de } \\
\text { recursos y entendimiento. }\end{array}$ & $\begin{array}{l}\text { - Implantación de la renta mínima universal. } \\
\text { - Ayudas a autónomos. } \\
\text { - ERTEs. } \\
\text { - Cierre de negocios. } \\
\text { - Impacto en el comercio. }\end{array}$ \\
\hline $\begin{array}{l}\text { CERTIFICADOS DE } \\
\text { SALUD Y MOVILIDAD } \\
\text { EXTERIOR } \\
\text { (LIBERTADES } \\
\text { PÚBLICAS) }\end{array}$ & $\begin{array}{l}\text { Para autorizar el libre albedrío, expedidos } \\
\text { por los jueces de paz. }\end{array}$ & $\begin{array}{l}\text { - } \text { ¿Pasaporte sanitario? } \\
\text { - Privilegios de los ya vacunados. } \\
\text { - } \text { Percepción de la coartación de derechos y } \\
\text { libertades. }\end{array}$ \\
\hline
\end{tabular}

\section{Conclusiones}

Podemos decir que:

1. El Diario del año de la peste reúne buena parte de las características generales de las enfermedades descritas en la literatura para los aspectos analizados en este trabajo: nosología médica, sociología de la medicina y aspectos sociales de la misma. Esto la convierte en un texto adecuado para la formación de estudiantes de medicina.

2. Los aspectos más relevantes de la nosología médica relacionados con la peste bubónica, tales como origen, transmisión, manifestaciones, diagnóstico y tratamiento, quedan recogidos en la obra de Defoe.

3. De forma similar, la organización de la asistencia sanitaria, la demografía sanitaria, las medidas públicas de actuación en situación de epidemia, y el comportamiento de los profesionales sanitarios, como integrantes de la Sociología de la Medicina, también están recogidos en el Diario del año de la peste.

4. Globalmente considerado, las pautas generales de actuación ante crisis sanitarias permanecen constantes a lo largo de los siglos. El aislamiento social, la evitación de contagios, 


\section{SIMILITUDES Y DIFERENCIAS ENTRE EL DIARIO DEL AÑO DE LA PESTE \\ Y LA ENFERMEDAD POR COVID-19 \\ SARA DE ARRIBA IGLESIAS; AGUSTÍN HIDALGO BALSERA}

las recomendaciones preventivas, la organización asistencial de emergencia, la activación de los sistemas de información sanitaria, las ayudas sociales, pueden identificarse tanto en la epidemia de Londres de 1665 como en la actual pandemia por COVID-19. Los elementos diferenciales relacionados con la demografía sanitaria, las instalaciones hospitalarias, la asistencia y el tratamiento son fruto del desarrollo científico técnico y social de cada momento.

5. Existen correlatos entre las medidas sociales adoptadas en la epidemia de peste bubónica de Londres de 1665 y la pandemia por COVID19 tales como las ayudas sociales, la protección del empleo, los factores predisponentes a la enfermedad y/o como causa de mortalidad, el control de la movilidad, la intervención de las libertades públicas, el comportamiento de los ciudadanos, la preocupación por la evolución económica y social posterior a la crisis sanitaria y la percepción de que es necesario un cambio de rumbo para evitar o paliar futuras crisis.

6. Por todo ello consideramos que se trata de una obra recomendable para entender, al menos parcialmente, cómo ha evolucionado el abordaje de las epidemias en los aspectos médicos y sociales derivados de ellos a lo largo del tiempo, a la vez que resulta una obra que «nos aproxima con precisión a nuestra crisis epidémica de $2020 »^{40}$.

\section{Referencias}

1. Fueyo J. Viral. La historia de la eterna lucha de la humanidad contra los virus. Barcelona: Penguin Random House, 2020.

2. Hidalgo Balsera A, Hidalgo Cantabrana C. Literatura y enfermedad, dos narrativas diferentes de procesos compartidos. Rev. Med. Cine. ;11(4):222-233.

3. Hidalgo A. Algunas características generales de los textos literarios relacionados con la enfermedad. Rev. Med. Cine. [Internet]. 2016; 12(2):78-81.
4. Vázquez-Espinosa E, Laganà C, Vázquez Valdés F. SARS Cov-2 y sus metáforas. Rev. Med. Cine. 2021;16(e):173-181; disponible en: https://doi. org/10.14201/rmc202016e173181.

5. Sontag S. La enfermedad y sus metáforas. El sida y sus metáforas. Barcelona: Penguin Random House; 2015.

6. Spinney L. El Jinete Pálido. 1918: la epidemia que cambió el mundo. Barcelona: Crítica; 2017.

7. Shah S. Pandemia. Madrid: Capitán Swing ; 2020.

8. Porras Gallo MI. La gripe española, 1918-1919. La pandemia que cambió nuestras vidas y retó a la medicina y los profesionales sanitarios españoles. Madrid: Catarata; 2020.

9. Defoe D. Diario del año de la peste. 2. lona: Alba Clásica; 2020.

10. Deville P. Peste \& Cólera. Barcelona: Anagrama; 2014.

11. Cereijido M. La ciencia como calamidad. 2 a ed. Barcelona: Gedisa; 2012.

12. Saborido C. Filosofía de la medicina Madrid: Tecnos; 2020.

13. Vespignani A. Prever la próxima pandemia. En Salud Global. El reto de las enfermedades infecciosas en la era de la globalización. Temas. Los Monográficos de Investigación y Ciencia. 2018; (94):87-93.

14. Muller CP. Do asymptomatic carriers of SARSCOV-2 transmit the virus? Lancet Reg Health Eur. 2021;4:100082.

15. Belmin J, Lafuente-Lafuente C. The challenge of asymptomatic SARS-CoV-2 transmission in care homes. Lancet Reg. Health. Eur. 2021;3:100051.

16. Jeffery-Smith A, Dun-Campbell K, Janarthanan R, Fok J, Crawley-Boevey E, Vusirikala A, et al. Infection and transmission of SARS-CoV-2 in London care homes reporting no cases or outbreaks of COVID-19: Prospective observational cohort study, England 2020 [Internet]. Lancet Reg Health Eur. 2021;3:100038.

17. Siff EJ, Aghagoli G, Gallo Marin B, Tobin-Tyler E, Poitevien P. SARS-CoV-2 transmission: a sociological review [Internet]. Epidemiol. Infect. 2020;148:e242.

Rev. Med. Cine. 2021; 17 (4), 315-335 Ediciones Universidad de Salamanca / @®@ J. Med. Mov., 2021; 17 (4), $315-335$ 


\section{SIMILITUDES Y DIFERENCIAS ENTRE EL DIARIO DEL AÑO DE LA PESTE \\ Y LA ENFERMEDAD POR COVID-19 \\ SARA DE ARRIBA IGLESIAS; AGUSTÍN HIDALGO BALSERA}

18. Zaki N, Mohamed EA. The estimations of the COVID-19 incubation period: A scoping reviews of the literature. J Infect. Public. Health. 2021;14(5):638-646.

19. Struyf T, Deeks JJ, Dinnes J, Takwoingi Y, Davenport $C$, Leeflang MM, et al. Signs and symptoms to determine if a patient presenting in primary care or hospital outpatient settings has COVID-19. Cochrane Database Syst. Rev. 2021;2:CD013665.

20. Tarazona $F$ ¿Es la suplementación de vitamina $D$ una terapia útil para la covid 19? Sociedad Española de Geriatría y Gerontología [Internet] 5 de abril de 2021.

21. Park JJH, Mogg R, Smith GE, Nakimuli-Mpungu E, Jehan F, Rayner CR, et al. How COVID-19 has fundamentally changed clinical research in global health. Lancet Glob. Health. 2021;9(5):e711-720.

22. González M y López-Fonseca. El Gobierno atribuye a la falta de datos fiables los errores al inicio de la pandemia. El País [Internet]. 5 de mayo de 2021.

23. Cebrián JL. El Gobierno y los expertos. El País [Internet]. 6 de abril de 2020 .

24. Pendás B. Pandemia y democracia. El País [Internet]. 25 de mayo de 2020.

25. Morillo I. Ai Weiwei: «El capitalismo ha llegado a su fin» El País [Internet]. 25 de mayo de 2020.

26. Hidalgo A. Cien años después y varias epidemias más tarde llegó la COVID-19. Rev. Med. Cine. 2021;16(e):1-6. https://doi.org/10.14201/rmc202016e0105.

27. Bassets L. No es un virus, es una época El País [Internet]. 12 de marzo de 2020.

28. Rojo-Alba S, Melón García S, Boga JA, Vázquez Valdés F, Álvarez-Argüelles ME. Viviendo una pandemia. Rev. Med. Cine. 2021;16(e):269-275. https://doi. org/10.14201/rmc202016e271277.

29. Ferrero L. Todo irá bien El País [Internet]. 29 de agosto de 2020 .

30. Tull MT, Edmonds KA, Scamaldo KM, Richmond JR, Rose JP, Gratz KL. Psychological outcomes associated with stay-at-home orders and the perceived impact of COVID-19 on daily life [Internet]. Psychiatry Res. 2020;289:113098.
31. Phiri P, Ramakrishnan R, Rathod S, Elliot K, Thayanandan T, Sandle N, et al. An evaluation of the mental health impact of SARS-CoV-2 on patients, general public and healthcare professionals: A systematic review and meta-analysis. EClinicalMedicine. [Internet] 2021;34(100806):100806.

32. Benke C, Autenrieth LK, Asselmann E, Pané-Farré CA. Lockdown, quarantine measures, and social distancing: Associations with depression, anxiety and distress at the beginning of the COVID-19 pandemic among adults from Germany. Psychiatry Res. 2020;293:113462.

33. Appleby L, Richards N, Ibrahim S, Turnbull P, Rodway C,Kapur N. Suicide in Englandin the COVID-19pandemic: Early observational data from real time surveillance. The Lancet Regional Health - Europe. 2021:100110.

34. Philpot LM, Ramar P, Roellinger DL, Barry BA, Sharma P, Ebbert JO. Changes in social relationships during an initial «stay-at-home» phase of the COVID-19 pandemic: A longitudinal survey study in the U.S. Soc. Sci. Med. [Internet]. 2021;274:113779.

35. Speaking of Psychology: Why people believe in conspiracy theories, with Karen Douglas, PhD. American Psychological Association [Internet]. January 2021.

36. Valcárcel A. Miedo al miedo. El País [Internet]. 16 de abril de 2020 .

37. Cantabrana B, Cobián N, Hidalgo-Cantabrana C, Hidalgo A. La crisis del coronavirus vista desde un diario de difusión nacional. Evolución enero-junio de 2020 Rev Med Cine. 2021;16(e):137-154.

38. Mair S. Neoliberal economics, planetary health, and the COVID-19 pandemic: a Marxist ecofeminist analysis. The Lancet Planet Health. 2020;4(12): e588-596.

39. Doncel L. «Esta crisis nos enseña que nuestras prioridades estaban equivocadas». El País [Internet]. 17 de junio de 2020.

40. Horton R. Covid-19. La catástrofe. Que hicimos mal y cómo impedir que vuelva a suceder. Barcelona: Antoni Bosch editor; 2021. 


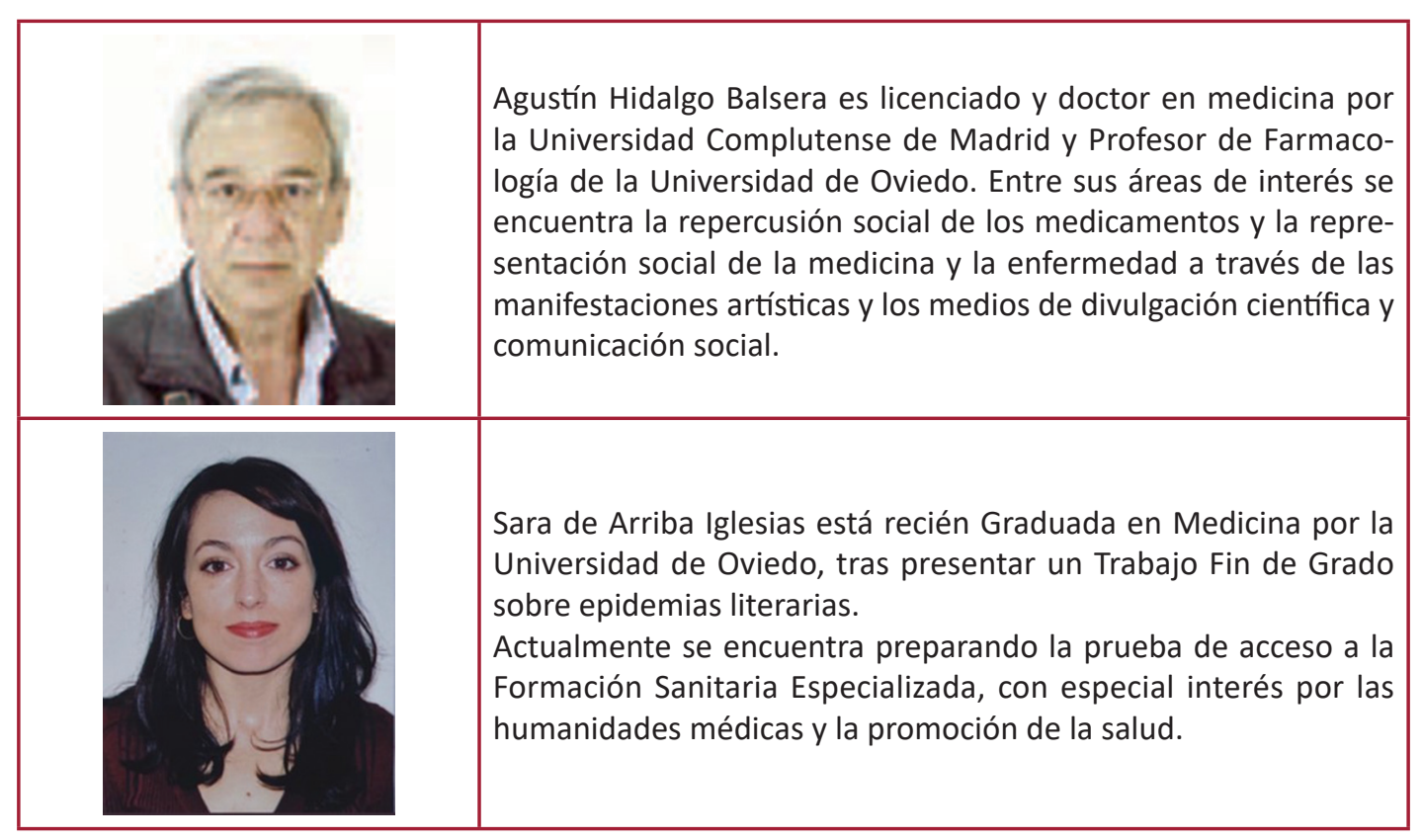

